\title{
COVID-19, the Masked Villain in Plain Sight
}

\author{
Emmanuel Unwaha $^{1 *}$ and Obehioye Enabor ${ }^{2}$ \\ ${ }^{1}$ Department of Obstetrics and Gynaecology, West Suffolk Hospital NHS Foundation \\ Trust, United Kingdom \\ ${ }^{2}$ Gynaecology Services Unit, Leicester General Hospital, University Hospitals of \\ Leicester NHS Trust, United Kingdom \\ *Corresponding Author: Emmanuel Unwaha, Department of Obstetrics and \\ Gynaecology, West Suffolk Hospital NHS Foundation Trust, United Kingdom.
}

Received: March 22, 2021

Published: March 29, 2021

(C) All rights are reserved by Emmanuel

Unwaha and Obehioye Enabor.

\begin{abstract}
The celebration of International Women's day is often a time to highlight the significance of a systematic, directed, effective approach to the diverse conditions that impinge on women's health. The world is in a desperate situation due to the ravaging effect of the COVID-19 pandemic; many countries have struggled to cope with the virus leading to a desperate race for vaccine development and the start of aggressive vaccination campaigns.

Unfortunately, the burden of diseases and conditions affecting women-pregnancy related complications, gynaecological cancers, reproductive health care and mental health continue to inflict pain in our women's lives. This has only been made worse by the pandemic as health workers find themselves and our women engulfed in a mental health crisis, confronted with difficult decisions in cancer care and distracted by the arrival of a new villain in the sphere of women's healthcare with grave implications for developing countries.
\end{abstract}

Keywords: Coronavirus; COVID-19; Pandemic; Women; Healthcare

Following the celebration of International Women and Mothers' days recently, it is important to evaluate the effect of the COVID-19 pandemic on women and women's health. Worldwide, the already precarious condition of women's health in several countries has been set back further by the pandemic. The burden of caring for patients with the virus appears to have altered the direction of priorities, research and resources; this will put women's chances at a decent livelihood and fulfilling existence in danger.

At the end of another busy day on the labour ward, I adjust my mask and reflect with a colleague on the global state of women's health and the girl child, hoping that common sense will prevail with all stakeholders enabling us to break free from the vicious cycle that is spinning out of control because of the Virus.
Since the outbreak of the SARS-CoV-2 virus in Wuhan, China in December 2019, case fatality ratios have gone as high as $25 \%$ in some countries [1]. Pregnancy with COVID-19 was associated with higher risk of hospitalisation, ICU care and need for ventilation in an American study; a mortality rate of $12.7 \%$ was found in a study from Brazil [2]. In the United Kingdom, the RCOG has confirmed a higher rate of intensive care admissions, premature delivery in unwell women with COVID-19 and higher admission rates in pregnant women of black, Asian and minority ethnic (BAME) background [3].

The existence of a pandemic is common knowledge but you would probably wonder what the reasons are behind my deep reflections?

Citation: Emmanuel Unwaha and Obehioye Enabor. “COVID-19, the Masked Villain in Plain Sight". Acta Scientific Women's Health 3.4 (2021): $45-47$. 
In Europe and America, women have been in an age-long grapple with workplace inequalities, sexual harassment and domestic violence. Before the pandemic, there were concerted efforts extended worldwide to reduce mortality rates from cardiac-related causes, thrombosis, post-partum haemorrhage, sepsis and eclampsia. These efforts appear to be diminished now that the Virus is here.

Mental health has been adversely affected by the government lockdowns; most frontline health care workers are women and a greater proportion of other women are finding it hard to stay positive, deal with the increased challenges of caring for the home and the economic hardship due to business closures and job losses [4]. Data from the UK has shown an increase in domestic abuse offences and demand for domestic abuse services during the pandemic [5]. This had led to significant strain on mental health care and social service facilities. The lockdown restrictions have also led to inconsistent exercise routines, lack of outdoor activities, poor eating habits, increased smoking and alcohol consumption that will further increase the likelihood of obesity and cardiovascular accident risks.

As the pandemic progressed, most hospitals in the UK have had to cancel elective cases in a bid to ensure workplace safety, social distancing rules and face- to- face services have been crippled. This had led to the rise of virtual clinics as a means of ensuring continued care.

There have been efforts to preserve cancer services but there is still a lag in accessing care; research from the Jo's cervical cancer trust suggest that 2 in 5 women are less likely to see their GP if they have symptoms due to fears of overstretching the service or contracting the virus [6]. There is a potential increase in cancer diagnoses in future from these delays as curable cancers are likely to become upgraded.

Other unfortunate developments related to the pandemic are an upsurge in perinatal deaths, partially due to inadequate care seeking due to fear of the virus-many women opt to use their own Doppler devices to monitor babies with sometimes heart-breaking consequences.

In Africa and other parts of the developing world, women are in the depths of the poverty endemic. In Nigeria, for example, the annual health budget is $<5 \%$ for a population of approximately 200 million people and over half of them being women $[7,8]$. The lifetime risk of a woman dying in Nigeria from childbirth is as high as 1 in 22 and majority of these women have to pay out of pocket for healthcare [9].

It is not surprising that pregnant mothers are not attending antenatal care regularly as hospitals are rapidly losing their best health care workers to economic migration or poor resource allocation from the government. There is a dearth of skilled birth attendants such as community midwives leaving the women to the vagaries of quacks and untrained individuals in septic environments.

The high fertility rates, poverty, lack of education and a plethora of communicable and chronic diseases in the setting of a COVID-19 pandemic threaten to lead to an unmitigated disaster in the next couple of years. This may sound like hyperbole but with the lack of functional health institutions, dwindling numbers of health care workers and providers, the rise in terrorism and insecurity, developing countries like Nigeria are likely to see the lives of their women hanging in the balance throughout the reproductive cycle.

As we conclude our discourse, it's heartening to realise that the challenges do have some solutions. The arrival of vaccines is welcome and a continued roll out with a quick lifting of lock down restrictions will provide protection for the population and restart the economy. Health education campaigns highlighting the necessity of the vaccine and debunking conspiracy theories and myths remain a priority.

It is highly likely that the economic fallout from COVID-19 will continue for some time; subsidies and financial packages like the stimulus checks and furlough schemes in the US and UK will have to continue. In developing countries, attention must be drawn to reviving small businesses, manufacturing and increasing the minimum wage. Global preparation must commence for the mental health epidemic, including domestic abuse by increasing government funding towards mental health and supporting charities, nongovernmental organizations and companies that work in this area. Another crucial aspect of stemming the tide is continued research and data collection. While the COVID pandemic remains, effort must also be steered towards data collection for new maternal care indices and the major causes of maternal mortality.

Citation: Emmanuel Unwaha and Obehioye Enabor. “COVID-19, the Masked Villain in Plain Sight". Acta Scientific Women's Health 3.4 (2021): $45-47$. 
Following the celebrations for the International Women's day of 2021, let us remember that when one part of us ails, we all are sick and when we win, the victory is shared. We will overcome the Virus but let us continue to fight to save every life haemorrhaging all over the world from its direct and indirect effects. We need our women; therefore, we must redouble our efforts in preserving their lives.

\section{Conflict of Interest}

The authors have no conflict(s) of interest to declare.

\section{Bibliography}

1. WHO. "Estimating mortality from COVID-19". Scientific brief.

2. Elizabeth A N Wastnedge., et al. "Pregnancy and COVID-19". Physiology Review 101.1(2021): 303-318.

3. RCOG. "Coronavirus infection and pregnancy: information for pregnant women and their families".

4. Ahmed A. "Why has COVID-19 impacted the mental health and well-being of women the most?" September (2020).

5. Office for National Statistics (ONS). "Domestic abuse during the coronavirus(COVID-19) pandemic, England and Wales" (2020).

6. Young Fabians. "The impact of COVID-19 on women's health".

7. Akinwotu E. "Nigeria to cut healthcare spending by $40 \%$ despite coronavirus cases climbing".

8. Knoema.com. Nigeria demographics: Population.

9. WHO. "Sexual and reproductive health: Maternal health in $\mathrm{Ni}$ geria: generating information from action".

\section{Assets from publication with us}

- Prompt Acknowledgement after receiving the article

- Thorough Double blinded peer review

- Rapid Publication

- Issue of Publication Certificate

- High visibility of your Published work

Website: www.actascientific.com/

Submit Article: www.actascientific.com/submission.php

Email us: editor@actascientific.com

Contact us: +919182824667

Citation: Emmanuel Unwaha and Obehioye Enabor. "COVID-19, the Masked Villain in Plain Sight". Acta Scientific Women's Health 3.4 (2021): $45-47$. 